\title{
Posterior Cranial Fossa Meningioma
}

National Cancer Institute

\section{Source}

National Cancer Institute. Posterior Cranial Fossa Meningioma. NCI Thesaurus. Code C6775.

A mening ioma that affects the posterior cranial fossa. 